\title{
A Pragmatic Study of Image Restoration via Corporate Apology in Chinese Internet Corporations
}

\author{
Zhanghong $\mathrm{Xu}^{1} \&$ Alan $\mathrm{Yan}^{1}$ \\ ${ }^{1}$ School of English for International Business, Guangdong University of Foreign Studies, Guangzhou, China \\ Correspondence: Zhanghong Xu, School of English for International Business, Guangdong University of \\ Foreign Studies, Guangzhou, China
}

Received: April 13, 2020

Accepted: May 17, 2020

Online Published: May 19, 2020

doi: 10.5539/elt.v13n6p76

URL: https://doi.org/10.5539/elt.v13n6p76

\begin{abstract}
With the booming of Chinese internet corporations, various wrongdoings have been frequently exposed to the public, which damages their corporate image. To face the challenge, these companies usually resort to apologies for image restoration. This study investigates how apology strategies are employed by Chinese internet corporations to restore image in the event of wrongdoings. Based on a self-built corpus and by means of textual analysis, we identified different apology strategies characterized by various linguistic features. The results show that "Illocutionary Force Indicating Devices (IFIDs)" and "damage repair" are two of the most frequently used move types which are normally marked by such key linguistic features as personal pronouns, modal verbs, performative verbs and intensifiers. It is also found that IFIDs, "giving account" and "admitting mistakes", "offering repair" and "inviting further interaction" are often incorporated together to show the company's sincere apologetic stance which contributes to the ultimate goal --- rebuilding corporate image and regaining the public's trust. However, direct expressions of "asking for forgiveness" are seldom found in apologies crafted by Chinese internet corporations. This study on apologies in the domain of internet corporations is believed to shed light on research on corporate apology in particular and corporate image restoration in general.
\end{abstract}

Keywords: corporate apologies, image restoration, pragmatic strategies, linguistic features

\section{Introduction}

Recent years have witnessed the increasing exposure of high-profile wrongdoings and misconducts from Chinese internet companies, ranging from the vicious competition between Qihoo and Tencent and the shocking Didi killing incident to the layoffs scandal at NetEase. When a crisis hits, an organization needs to formulate and deliver a response to its stakeholders and the general public in order to protect its corporate reputation (Coombs, 1999). Under this condition, companies often resort to apology as part of their responses, but not all apologies are successful at repairing public perceptions. Therefore, how to manage an appropriate apology distinguishes itself in diffusing crises and restoring corporate reputation. Although an increasing number of research on corporate apologies (Burnett, 2002; Kim, 2004; Coombs \& Holladay, 2008; Kampf, 2009) have been conducted in recent years, few studies have examined apologies initiated by internet corporations whose business covers all aspects of daily life and profoundly affects the society. Review of research on internet corporation (Shuai, 2005; David, 2005; Wang, 2012; Luo \& Liu, 2012; Zhang, 2014) reveals that it has become a hot research topic for nearly two decades, especially from economic and managerial perspectives. While, there are still topics and phenomenon remained largely unexplored concerning internet corporations, such as the elaborately crafted apologies when they face a crisis situation. To fill this gap, this study is designed to identify the distinctive apologizing patterns and characteristics embedded in apologies posted by Chinese internet corporations and explore how corporate image can be restored via apology strategies.

This study seeks to address the following three questions. (1) What moves and strategies are employed in corporate apologies delivered by Chinese internet corporations? (2) What linguistic devices/features can be identified in issuing corporate apologies by Chinese internet corporations? (3) How do these apology strategies contribute to the corporate image restoration?

This study is structured as follows. Section 2 reviews related studies on corporate apologies and image restoration, and Section 3 presents the theoretical background of the study. Section 4 focuses on the detailed analysis of the data, followed by the conclusion of the study in Section 5 . 


\section{Literature Review}

This section begins with the review of related studies on corporate apologies and image restoration, followed by an evaluation of the relation between corporate apologies and image restoration.

\subsection{Corporate Apologies}

Corporate apology is commonly viewed as an organization's statement of acknowledging responsibility and asking for forgiveness when engaging in activities that violate the trust of the public (Burnett, 2002; Kim, 2004; Coombs \& Holladay, 2008). In recent years, corporate apologies have become commonplace, and crisis researchers have emphasized that apologies are the best crisis response strategy when companies are responsible for the crisis (Raju \& Rajagopal, 2008).

Corporate apologies have so far attracted much attention from diverse disciplines, in which linguistics and communication studies prevail. In terms of linguistic approach to corporate apologies, numerous studies have been made from the perspective of pragmatics (e.g., Olshtain 1983; Blum-Kulka et al., 1989; Kampf, 2009), taking corporate apology as a speech act. To be specific, researchers in this field regard apology as an act of expressing regret, assuming or reducing responsibility instead of just an announcement of the fact that someone did something wrong. Within pragmatics, researchers are also interested in exploring the realization of corporate apology. Olshtain (1983) proposes Cross-Cultural Speech Act Realization Patterns which generally contains an expression of apology; an acknowledgement of responsibility; an explanation or account of the situation; an offer of repair; a promise of forbearance. The pragmatic study on corporate apology has shed some light on the interpretation and realization of communicative purposes in apology genre. But some other factors, such as social and cultural contexts that also exert certain effect on apology are often neglected in the above pragmatic studies.

In terms of communication studies on corporate apology, corporate apology is widely employed in crisis communication and public relations maintenance. In the above two fields, apology is often regarded as a strategic device utilized to restore damaged reputation and maintain the relationship between the company and the client (Benoit, 1997; Pace et al., 2010; Compton, 2016). Recent research trends have concentrated more on revealing the effects of corporate apologies with the complementary perspectives of pragmatic and communication approaches (Suman \& Surin, 2012; Verhoeven et al., 2012; Ten Brinke \& Adams, 2015; Young \& Lucy, 2019).

Despite great significance attached to the function and effects of corporate apologies, the characteristics and patterns of corporate apologies in a specific area have inadequately been examined. Therefore, how apology strategies are employed for image restoration in different domains should be investigated in much greater depth.

\subsection{Image Restoration}

The literature on image restoration has been prolific over the last decade (Benoit, 1995; Coombs \& Schmidt, 2000; Burns \& Bruner, 2000). Through summarizing many research results, Benoit (1995) proposes five strategies for image restoration: denial, evasion of responsibility, minimization, corrective action, and mortification. Benoit's image restoration theory (Benoit, 1995, Benoit, 1997) and its successive revisitation have been the dominant paradigm when studying crisis communication over the last decade. Benoit notes that image repair apology is necessary when: (1) an offensive act has occurred, and (2) an individual or organization has been accused of being responsible for that act.

Scholars have applied image restoration to a wide array of research subjects, from organizations (Meng, 2010; King, 2006), politicians (García, 2011) and celebrities (Kauffman, 2012) to universities (Fortunato, 2008) facing with the allegations of wrongdoing. In these studies, image restoration strategies are found to handle the immediate aftermath of an incident and maintain public relations, with either successful or unsuccessful consequences. In recent years, the great impact of the emerging new media has inspired some researchers to probe into the effects of social media platforms, such as Facebook, Twitter, and Instagram, and image restoration strategies in crisis communication (Muralidharan, 2011; Rasmussen, 2015; Du Plessis, 2018; Triantafillidou \& Yannas, 2020). They look into the interplay between new social media and crisis communication, aiming to effectively exploit and wield the opportunities and benefits generated by social media on strategic crisis management.

\subsection{Corporate Apology and Image Restoration}

Benoit (1997) establishes image restoration model based on two notions: communication is goal-directed activity, and maintaining a favorable reputation is a key goal of communication. Since then, a great number of researchers have been dedicated to revealing how image repair works in specific contexts in which corporate apology is one 
of the preferred strategies for image repair.

In choosing apology strategies, scholars have agreed that managers should be cautious when using image restoration strategies in the event of an organizational wrongdoing (Coombs, 2004; Coombs \& Holladay, 2002; Benoit, 1995). Not all strategies fit into the situation and are conducive to eliminating the crisis and repairing tarnished image. Coombs (2004) advocates that crisis response strategies vary with crisis types, and identifying the crisis type provides an initial assessment of the reputational threat by indicating the level of crisis responsibility associated with the crisis. Likewise, characteristics of the wrongdoing may also play a key role in the selection of an appropriate response strategy (Coombs \& Holladay, 2002). With respect to the number of strategies which are appropriate for image restoration, Benoit (1995) theorized that companies accused of a serious transgression will attempt to protect their image by employing one or more image restoration strategies. Crisis managers can use a combination of crisis response strategies but they must be sure to avoid contradictions (Ilhen, 2002). The corporate image repair was much more effective when the company involved apologized and meanwhile instituted corrective action (Benoit \& Brinson, 1994).

In regard to the effectiveness of image restoration strategies in crisis management, scholars hold varying opinions. Benoit and Shirley (1997) conclude that apologies are likely to be effective in dealing with problematic situations, and they differ in the degree of effectiveness. Corrective action is perceived as more effective and appropriate than most image restoration options, whereas denial, provocation, minimization, and bolstering are reported to be least appropriate and effective. On the contrary, Coombs \& Holladay (2008) argue that apology should not be used as a universal strategy, and it would be significant to weigh the pros and cons of the consequences of apology. Ulmer et al. (2007) observe that the focus of image restoration is limited primarily to post-event discourse and to the communication specifically associated with accusations and responses.

Studies on apologies and image restoration up to now have tended to specify the contexts of apologizing and explore the effectiveness of different strategies. However, few of them take account of the differentiation of area-based corporations when selecting image restoration strategies.

\section{Theoretical Background}

This section elaborates on the theoretical foundation for this research, covering speech act theory and the act of apology, and move and strategy identification.

\subsection{Speech Act Theory and the Act of Apology}

Speech Act, an influential theory on the actual communicative function of language, tries to explore to what extend impartial interaction is possible between speakers. First put forward by John Austin (1962) in his work How to Do Things with Words, speech act theory is based on the main principle that the uttering of a sentence is, or is part of, an action within the framework of social institutions and conventions. In other word, saying is doing. In developing speech act theory, Austin proposes that utterances can perform three acts at the same time: locutionary act, illocutionary act and perlocutionary act. Searle (1976) puts forward a more detailed system, in which he divides illocutionary acts into five categories: assertives, directives, commissives, expressives and declarations. Furthermore, an effective speech act can only be made based on four felicity conditions: (1) prepositional content condition; (2) preparatory condition; (3) sincerity condition; and (4) essential condition.

Apology, as an illocutionary speech act (Austin, 1969), falls into the category of "expressive" (Searle, 1979) which shows "the speaker's psychological state specified in the sincerity condition about a state of affairs specified in the prepositional content." (Searl, 1979: 275). In Cross-Cultural Speech Act Realization Patterns (CCSARP) project (Olshtain, 1983), three preconditions, which must hold true for the apology act to take place, are advanced as follows:

a. S did X or abstained from doing $\mathrm{X}$ (or is about to do it).

b. X is perceived by S only, by H only, by both $\mathrm{S}$ and $\mathrm{H}$, or by a third party as a breach of a social norm.

c. $\mathrm{X}$ is perceived by at least one of the parties involved as offending, harming, or affecting $\mathrm{H}$ in some way.

The act of apologizing can be realized by IFIDs (Illocutionary Force Indicating Devices) and expression of responsibility. IFIDs, the most direct realization of an apology, are often characterized by formulaic expression such as sorry, apologize, regret and excuse, which can be intensified by such linguistic devices as adverbials (very, terribly) and repetition. Apart from IFIDs, the apology speech act set includes four potential strategies for performing the act of apologizing: (1) an explanation or account of the cause which brought about the offence; (2) an expression of responsibility for the offence; (3) an offer of repair; (4) a promise of forbearance (BlumKulka \& Olshtain, 1984). 
In general, apology, as a speech act that requires an action and / or an utterance, is intended to provide support or make excuse for certain behavior and set things right. Just as Olshtain and Cohen (1983) demonstrate, each speech act has a schematic structure and consists of a certain frequently conducted strategies that are named as "speech act set". Like other speech acts, apology is also realized by a set of strategies. Therefore, it is quite necessary to reveal the speech act patterns employed in those corporate apologies from pragmatic perspective, which is believed to provide insights for internet corporations to better draft apologies when they are trapped in crisis.

\subsection{Move and Strategy Identification}

Move analysis, initiated by Swales (1990) and further developed by Bhatia (1993), is one of the most widely applied models in terms of apology genre analysis. Swales proposes that a move is a segment unit or element within a written or spoken text used to achieve a particular purpose that contributes to the fulfillment of the overall purpose. According to Bhatia, strategy, as the lower-level unit under move, reveals how the speaker or writer chooses to realize the move and further achieve their communicative purposes. Apology, a typical speech act with intended purposes, usually can be realized by different moves and strategies. Apart from the five-type classification of apology strategies advanced in the CCSARP project, there are still classifications sorted out by other researchers. For instance, Trosborg (1987) summarizes seven types of apology strategies: (0)refusal to acknowledge guilt or refusal to apologize; (1)minimizing the degree of offence; (2)acknowledgement of responsibility; (3)explanation or account; expression of apology; (4)offer of repair; (5)promise of forbearance; (6)expressing concern for the hearer. It is found that those categorizations of apology strategies, abstracted from their chosen corpus, have many overlaps. Therefore, by referring to existing categorizations and carefully examining apologies in the data, six move types and their respective strategies have been identified in the corpus and presented as follows.

Table 1. Move Types and Strategies Identified in the Corpus

\begin{tabular}{cc}
\hline Move Types & Strategies \\
\hline Move 1: Extending Explicit \\
Apology(IFIDs) & Strategy 1a: offering apology \\
Move 2: Giving Account & Strategy 2a: describing the event \\
& Strategy 2b: making excuses \\
Move 3: Acknowledging Responsibilities & Strategy 3a: admitting mistakes \\
& Strategy 3b: lack of intent \\
Move 4: Damage Repair & Strategy 3c: expressing sadness \\
& Strategy 4a: offering general repair \\
Move 5: Image Repair & Strategy 4b: offering specific repair \\
Move 6: Relationship Repair & Strategy 5: highlighting corporate culture \\
& Strategy 6a: fulfilling the readers' human-relations wants \\
& Strategy 6b: inviting further interaction \\
\hline
\end{tabular}

\section{Data Analysis}

This section will first introduce how data are collected and analyzed, and then concentrate on the analysis of move and apology strategies, which are followed by linguistic feature analysis, and finally explore how Chinese internet companies employ apology strategies to repair corporate image.

\subsection{Data Collection and Research Methods}

The data, consisting of 30 corporate apologies posted by 12 famous internet companies in China, such as Tencent, Alipay, Ctrip, Baidu, etc., are collected through varied channels like corporate official websites, WeChat official account and Sina Weibo. The data sample used for analysis mainly takes the form of public letters and statements.

Both quantitative and qualitative methods are adopted to analyze the data. The quantitative method, assisted by the concordance tool AntConc 2019, is used to quantify the frequency of apology strategies and linguistic devices within the dataset and to identify trends for follow-up qualitative analysis. With respect to the qualitative method, we analyze each extract from different cases. Functions and features of apology strategies are to be 
expounded with specific examples to reveal their respective communicative purposes intended by Chinese internet corporations.

\subsection{Move Types and Strategies Analysis}

In what follows, the distribution and frequency of move types and strategies are presented, followed by a detailed analysis of each move and strategies in these apologies to reveal their function in image restoration.

Table 2. Distribution and Frequency of Move Types and Strategies

\begin{tabular}{cccc}
\hline Move Types & Strategies & Times & Percentage \\
\hline Move 1: Extending Explicit & Strategy 1: offering apology & 56 & $24.88 \%$ \\
Apology(IFIDs) & Strategy 2a: describing the event & 23 & $10.22 \%$ \\
Move 2: Giving Account & Strategy 2b: making excuses & 12 & $5.33 \%$ \\
& Strategy 3a: admitting mistakes & 28 & $12.44 \%$ \\
Move 3: Acknowledging & Strategy 3b: lack of intent & 3 & $1.33 \%$ \\
Responsibilities & Strategy 3c: expressing sadness & 6 & $2.66 \%$ \\
Move 4: Damage Repair & Strategy 4a: offering general repair & 29 & $12.88 \%$ \\
& Strategy 4b: offering specific repair & 29 & $12.88 \%$ \\
Move 5: Image Repair & Strategy 5: highlighting corporate culture & 8 & $3.55 \%$ \\
Move 6: Relationship Repair & Strategy 6a: fulfilling the readers' & 17 & $7.55 \%$ \\
& human-relations wants & & \\
& Strategy 6b: inviting further interaction & 14 & $6.22 \%$ \\
Total & Total & Total & Total \\
6 & 11 & 225 & $100 \%$ \\
\hline
\end{tabular}

Table 3. Frequency of Each Move Identified in the Corpus

\begin{tabular}{ccccccc}
\hline Move Types & Move 1 & Move 2 & Move 3 & Move 4 & Move 5 & Move 6 \\
\hline Times & 57 & 35 & 37 & 58 & 8 & 31 \\
Percentage & $25.33 \%$ & $15.55 \%$ & $16.44 \%$ & $25.77 \%$ & $3.55 \%$ & $13.77 \%$ \\
\hline
\end{tabular}

As is demonstrated in the above tables, the frequency of various moves and strategies used by Chinese internet corporations differs in the chosen corpus. As is illustrated in Table 3, Move 4: damage repair is used most frequently in the present corpus of internet corporate apologies, followed by move 1: extending explicit apology. In contrast, move 5 only takes up $3.55 \%$ in the whole category. With regard to Table 2 , the strategy of offering apology accounts for $24.88 \%$, the largest percentage in the whole category, followed by offering repair, admitting mistakes and describing the event in sequence. However, the strategy "lack of intent" within the move of acknowledging responsibilities is rarely used in those corporate apologies. Besides, it is worth mentioning that some other apologizing strategies such as "asking for forgiveness", "expressing regret" and "highlighting previous achievements" are nowhere to be found in the corpus.

\subsubsection{Move 1: Extending Explicit Apology (IFIDs)}

This move functions to show the company's apologetic stance in a straightforward way and is characterized by illocutionary force indicating devices, such as "apologize", "sorry", "forgive" and "regret". It is usually the first step that companies would adopt to dispel the public's negative emotions and feelings. Normally, this move can be realized by three strategies: offering apology, expressing regret and asking for forgiveness, which differ in their illocutionary force. In this part, only the strategy of offering apology is discussed in detail as there is no example of the latter two strategies in this corpus.

Strategy 1: offering apology

This strategy is often realized by using the verb "apologize" or its noun form "apology", to which prepositions such as "to" and "for" conventionally attached. In addition, the expression of apology can be intensified by adverbs like "sincerely", "wholeheartedly" and "deeply". 
(1) We deeply apologize for this.

(2) In this regard, we apologize to this ex-colleague and his family, as well as colleagues and the public affected by this - sorry, we did wrong.

In the above examples, expressions of apologies intensified by prepositions and adverbs are directly addressed to the intended hearers to obtain their forgiveness. These sincere expressions serve to motivate the audience to read the text, thus promoting further communication between the company and the audience.

\subsubsection{Move 2: Giving Account}

This move concerns itself with the restatement of the offense, including its cause, consequences. In virtue of the characteristics of internet companies, the recipients of their apologies include not only the direct victims of the offense but also their stakeholders and the general public. Therefore, it is necessary for the apologizing companies to first clarify the whole event in great detail so as to represent the full picture of what happened. This move can be achieved by some strategies that effectuate respective communicative purposes. In this corpus, two strategies are identified: describing the event and making excuses.

Strategy 2a: describing the event

This strategy is employed to depict what happens and what the consequences are, which is usually marked by specific time and formulaic structures.

(3) Regarding the promotion of "Shanghai Fuda Hospital" reported by CCTV on Sept. 12, 2018, we here make a special explanation to the users and media who are concerned about it.

The above expression gives an account of the time when the event happened and is embedded in the formulaic structure "reported by", which well informs the reader of the background information of this event.

\section{Strategy $2 \mathrm{~b}$ : making excuses}

This strategy provides explanation and excuses for the offensive event in an attempt to justify the misconduct. It can be realized by attributing responsibilities to external or internal factors that beyond the companies' control to preserve their reputation. Excuses within this strategy are marked by such expressions as "because of" and "the reason lies in that".

(4) According to the investigation, the reason for this misleading problem is that the name of Shanghai Fuda Hospital and the abbreviation of the related affiliated hospital of Shanghai Fudan University share certain semantic similarities, which has misled the medical treatment choices of netizens.

(5) In the news about the flood situation in Shandong just released, due to erroneous editing, the number of people killed in the copy was missing, and we immediately corrected the error when we discovered it.

In Example 4, the company employs a causal expression with reference to external factors, implicitly indicating that the offence was caused by factors beyond the company's control and thus disassociating the company from blaming. Example 5 demonstrates the internal factor that is described as a negligence of the company.

\subsubsection{Move 3: Acknowledging Responsibilities}

This move is applied when admitting and accepting the responsibility for the consequences of this offensive event, which can be actualized by strategies such as admitting mistakes, lack of intent and expressing sadness. Those apology strategies within this move differ in degrees of responsibility acceptance, from high level to low level in sequence. As is often the case, the more responsibility the company shoulders, the more satisfied the offended party will be and the more sincere the apology will be regarded as. However, the higher the level of responsibility acceptance is, the more threat will be posed to the company's negative face.

Strategy 3a: admitting mistakes

The strategy entails the highest level of responsibility acceptance within the category by explicitly and straightforwardly confessing the company's wrongdoings that lead to the offensive act. It is usually marked by such expressions as "fail to do something", "indeed poorly handled", "be responsible for something", and "feel guilty".

(6) In this incident, Ctrip not only failed to fulfill its due obligations, but also failed to pay enough attention to this case when consumers and supervisory agencies clearly responded. We are deeply ashamed of the trust that consumers and society have given to us.

(7) I will assume the leadership responsibility for the big problem with our product.

The above examples show that companies tend to use the strategy of taking on responsibility to construct and 
maintain their responsible images so as to gain the public's forgiveness.

\section{Strategy 3 b: lack of intent}

This strategy, often taking the formulaic expressions of good will, is intended to indicate that the act of the company is originally intended to do good deeds.

(8) It was intended to fully respect the user's right to know and let users know that only with their own consent, Alipay's annual bill can display their credit-free content. There is noting wrong with the original intention, but we did in a very silly way.

In the above example, the strategy "lack of intent" helps to clarify the company original intention to justify the reason of this offence.

Strategy 3c: expressing sadness

The expression of sadness entails a low level of responsibility as it merely conveys the company's negative emotion and feelings towards the consequence of the offensive act. This strategy is often realized by expressions like "feel grieved" and "feel sad", which can be further intensified by adverbs such as "very", "deeply" and so on.

(9) In the past few days, we have once again fallen into great pain and suffering. In just over three months, during the platform's security rectification, tragedy happened again. As the company's founder and president, I feel very sad and guilty.

The above apology is issued by the founder of China's largest mobile transportation platform - Didi after the occurrence of a murder case. By repeatedly employing empathetic terms, the apologizer attempts to show his sincere feeling of sadness concerning the consequence.

\subsubsection{Move 4: Damage Repair}

This move aims to inform the public what has been done and will be done to compensate damages caused by this offensive event. Compared with the statement of apologies, further remedial measures are normally considered more important by the offended part and the general public in terms of granting their forgiveness. Besides, the stakeholders and the public are also expected to see the company's efforts in preventing the recurrence of similar offenses. Therefore, this move actually serves the central function of image repair and trust restoration. It is embodied primarily in two strategies: offering general repair and offering specific repair.

Strategy 4a: offering general repair

Offering general repair refers to general remedial actions taken by the company to assure its customers. This strategy usually takes the form of promise by expressions such as "learn the lesson", "will" and "make a commitment", or by expressions conveying the company's promises to assume further responsibility.

(10) We will learn lessons from this incident and continue to strengthen the management of content review of promotion activity.

(11) We solemnly promise that in the future, if a security breach occurs and causes user losses, Ctrip will pay full compensation.

Strategy $4 \mathrm{~b}$ : offering specific repair

This strategy refers to the detailed remedies provided in time to tackle the damage. It is often marked by such terms as "immediately" and "punishment".

(12) We corrected this the moment we discovered it.

(13) JD.com has requested the store to delete relevant information the first time, and punished the store according to regulations.

\subsubsection{Move 5: Image Repair}

As corporate image is widely acknowledged to be the most valuable intangible asset of a company, every company will strive to repair its image and maintain its reputation for future development once a crisis occurs. This move can be actualized by highlighting corporate culture, history and previous achievements to remind and enhance readers' positive feelings about the company so as to mitigate the negative effects. Examples in this corpus only involve the strategy of highlighting corporate culture, which is presented as follows.

\section{Strategy 5: highlighting corporate culture}

This strategy is used to emphasize the philosophy, value, mission and goal that are consistently upheld by the 
company.

(14) In the face of the health of colleagues, Netease always believes that no matter what the ability and quality, and how much the performance contribution, our attitude to help colleagues through difficulties is consistent.

(15) JD.com has always attached great importance to the protection of customer information, and severely punished those who violated regulations.

\subsubsection{Move 6: Relationship Repair}

The main purpose of this move is to repair the broken relationship with affected customers as well as to maintain rapport with the general public. It is employed explicitly by fulfilling the audience's "human-relations wants" (Brown, 1987) and inviting further interaction to achieve the company's goal of winning back brand loyalty and expanding customer base. This move involves two strategies, namely fulfilling the reader's human-relation wants, and inviting further interaction.

Strategy 6a: fulfilling the reader's human-relation wants

According to Brown (1987), human-relation wants refers to the wants to be approved, admired, cared about, understood and so forth. In this strategy, expressions of compliments, appreciation and acceptance of criticism are normally used to show the company's yearning for the public's understanding and support.

(16) Here we pay our highest respect to all medical workers.

(17) We sincerely thank the supervision and guidance of Shenzhen Consumer Council and people from all walks of life.

Strategy $6 b$ : inviting further interaction

Through explicitly inviting and requesting the public to engage int the repair work, the strategy is applied to show the company's sincerity in assuming responsibility and making improvements in the future. This strategy is often accompanied by such terms like "please", "hope" and "welcome".

(18) Everyone is welcome to email us at jubao@qiyi.com to supervise and feedback the problems encountered during the interview. We will never leave room for any form of discrimination.

(19) We sincerely look forward to help and supervision over our rectification from all walks of life.

\subsection{Linguistic Feature Analysis}

The analysis of move types and strategies gives a macro description of corporate apologies, which is actually realized through linguistic features. In this part, a micro investigation of the linguistic features embedded in those apology strategies is conducted with word frequency and specific examples to identify their respective image restoration functions. Going further into the apology strategies, we found such salient linguistic features as person deixis, verb choices and intensifiers are prevalent in the corpus, which deserve in-depth exploration.

\subsubsection{Person Deixis}

Since the relationship between language and context is most obviously reflected through the phenomenon of deixis, it is of great significance to investigate the deixis, especially person deixis in the genre. Being interrelated with the specific time, place, task and so on, person deixis expresses the relationship among persons or things. In corporate apologies, the strategic using of person deixis helps exemplify the apologetic stance of the offender.

Table 4. Frequency of Person Deixis

\begin{tabular}{cc}
\hline Person deixis & Frequency of occurrence \\
\hline I & 29 \\
We & 147 \\
Our & 19 \\
You & 24 \\
Users & 41 \\
Society & 19 \\
Netizens & 12
\end{tabular}

Table 4 shows the frequency of different person deixis in the collected apologies. It is obvious that these companies prefer to use the first person in plural form "we" to address themselves. Besides, the pronoun "I", the 
possessive form "our" and noun of the company's name are also employed to address those companies themselves. But the first person singular form "I" occurs much less frequently than its plural form "we". The former is usually used by the CEOs to show their personal apologetic stance and responsibility, whereas the latter frequently represents the collective responsibility of the organization. The high frequency of "we" indicates that the apology is intended by all the staff in the company instead of someone alone. When it comes to the offended party, those companies prefer to use the noun "users", through which they make it clear that the apology is presented to their customers. The singular form and the plural form of "you" are also used to address the victim. Through examining the concordance of "you", we found that the pronoun "you" not only refers to the victim but also the general public and those companies' customers as well. In addition, the noun "society" is also a favorable addressing which suggests that those internet companies' wrongdoings will not only affect their users but also the whole society due to their growing impact. Since most of the internet company's commerce is online, they also refer to the victim as netizens. The above addressings are relatively informal which shorten the social distance with the public, and contribute to the ultimate goals - the construction of a responsible image and the reconstruction of relations with customers and the general public.

(1) We sincerely apologize to the netizens for the adverse effects.

(2) I would like to say sorry to all users who trust and like GIF, as well as friends who care about GIF.

(3) After Mr. Wang gave feedback, our company conducted an investigation immediately.

(4) Sincerely apologize to you again, and thank all parties for their supervision and criticism.

(5) We apologize to the society and the netizens.

\subsubsection{Verb Choices}

By verb choices is meant to refer to the high occurring frequency of the modal verb "will" and the performative verb "apologize".

Table 5. Frequency of Modal Verb "will”and Performative Verb "apologize"

\begin{tabular}{cc}
\hline Type of verb & frequency of occurrence \\
\hline Modal Verb / will & 59 \\
Performative Verb /apologize & 42
\end{tabular}

"Will" is the most frequently employed modal verb in the corpus, which is usually used after the pronoun "we" to show the company's promise of undertaking some remedial actions and preventing future occurrence of the wrongdoing. Through examining the occurrence IFIDs, we found that the performative verb "apologize" is used far more than "sorry", "forgive" or "regret" as the former is more formal and is a better choice to show their sincerity in extending explicit apology and acknowledging responsibilities.

(1) JD.com will be committed to continuously improving the management of third-party platform merchants and working with third-party merchants to enhance the user experience.

(2) Here, we apologize to our users and we will punish the relevant responsible personnel.

\subsubsection{Intensifiers}

Intensifier is another noteworthy linguistic device in the corpus, which usually takes such forms as adverbs and adjectives. They often serve to intensify the effect of apologizing and highlight the apologizer's sincerity.

Table 6. Frequency of Intensifiers

\begin{tabular}{cc}
\hline Intensifiers & frequency of occurrence \\
\hline Again & 17 \\
Sincerely/ sincere & 14 \\
Deeply/deep & 10 \\
Very & 8 \\
Solemnly & 8
\end{tabular}

As is shown in Table 6, intensifiers such as "again", "sincerely/sincere" and "deeply/deep" are frequently used together with IFIDs to enhance the expressing of apology.

(1) We here would like to say it again: sorry. 
(2) This is a mistake in our work, and we sincerely apologize to you all.

(3) This is a very serious work error, and we express our deep apology and introspection for the adverse social effects caused thereby.

\subsection{Corporate Image Restoration via Apology Strategies}

As has been discussed above, those moves and strategies actualized by various linguistic features or devices serve their respective functions in corporate image restoration. Intensifiers such as "again", "sincerely" and "deeply" and IFIDs, usually serving as the first step of apology, are employed to show the company's apologetic stance in a straightforward way and to dispel the public's negative emotions and feelings. In this process, internet companies prefer to address themselves as "we" or directly by the company's name in order to inform the public that the apology is intended by all the staff in the company. Considering the extensive impact of internet companies, and the wide range of recipients of their apologies (not only the direct victims of the offense but also their stakeholders and the general public), the companies will give a detailed account of what happened. Compared with the statement of apologies, further remedial measures are considered more important. Thus, the strategy of damage repair is adopted to inform the public what has been done and will be done to compensate damages. This strategy usually takes the form of promise characterized by such modal verbs as "will" and "must". Since the prime mission for the company is to restore image and rebuild reputation for future development, some companies tend to highlight corporate culture, history and previous achievements to remind and enhance readers' positive feelings about the company so as to mitigate the negative consequences. At the end of apologies, further interaction is extended to their users, netizens and even the whole society to show their sincerity in making improvements and to achieve the company's goal of winning back brand loyalty and expanding customer base. In the meantime, it is worth mentioning that those strategies are not totally independent from each other but are often incorporated together to contribute to the corporate image restoration.

\section{Conclusion}

This section will first introduce the findings of the research, focusing on the answers to the three questions formulated at the introduction section, and then present the implications and limitations of the study, and suggestions for further research.

This study analyzes apologies published by Chinese internet corporations from the pragmatic perspective (e.g., Searle, 1979; BlumKulka \& Olshtain, 1984), and obtained the three major findings.

Firstly, based on the models of apology strategies proposed by previous researchers, six moves are identified as the model for this study: Extending Explicit Apology (IFIDs); Giving Account; Acknowledging Responsibilities; Damage Repair; Image Repair; Relationship Repair. Moves of extending explicit apologies and damage repair are found to prevail over other moves in the corpus. Each move is realized by their respective strategies, and there are 11 strategies in total, which are marked by varying linguistic features and serve different communicative purposes. As the research result demonstrates, the strategy of directly extending apologies is used most frequently by Chinese internet corporations to show their apologetic stance. Syntactically, they are usually located in the beginning of the apology and repeated at the end of the text in order to manifest the company's sincerity in apologizing. Besides, strategies of offering general repair and admitting mistakes are also widely employed by internet companies to construct positive images and restore their relations with the public. However, Chinese internet corporations rarely utilize such strategies as expressing regret, asking for forgiveness and referring to corporate previous achievements in their apologies for wrongdoings.

Secondly, those strategies are realized through various linguistic devices such as person deixis, choice of specific verbs (modal verbs and performative verbs), and intensifiers. The high frequency of the first person plural form "we" shows that those corporate apologies are centered around the apologizing companies themselves instead of someone alone. When addressing the offended party, they prefer to employ "users", "you" and "the society". In terms of verb choices, the modal verb "will" enjoys a high keyness, which is a sign of making promise for damage repair. Besides, internet companies prefer to use the performative "apologize" intensified by "again", "sincerely" and "deeply" to show their sincerity in apologizing.

Thirdly, those strategies are often incorporated together to contribute to the corporate image restoration. Each apology in the corpus consists of more than two strategies which serve their respective functions. The strategy "offering apology", often appearing in the beginning of the text, is adopted to show the company's apologetic stance in a straightforward way. Strategies like "describing the event" and "making excuses" are usually used together with "offering apology" to represent the full picture of what happened. Meanwhile, companies also tend to employ the strategy of "acknowledging responsibility" to show their sympathy and sincerity in dealing with 
the consequences. Strategy of "offering repair" functions to inform the public what has been done and will be done to compensate damages caused by this offensive event. Some companies also adopt strategies such as "highlighting corporate culture" and "inviting further interaction" to win back brand loyalty.

From above analysis, it is advisable to adopt a combination of apology strategies according to the severity of their misconducts. Higher-level severity often requires sincere acknowledgment of mistakes and specific remedial actions. While lower-level severity of wrongdoings will be forgiven more easily, often accompanied by promise of future performance. In contrast, making excuses to avoid responsibility usually invites more fierce complaints and criticism.

However, the present research is mainly subject to two limitations. Firstly, the corpus of this study is not large enough, which might affect the reliability of the research result. Secondly, social factors, such as the seriousness of the event that can influence the use of strategies in apologies, are not discussed in detail.

Given the research limitations stated above, several suggestions are presented for future study on corporate apologies. First of all, to make a thorough and convincing research on corporate apologies in a specific area, more data are expected to be collected by multiple means. Secondly, a comparative study of apologies made by companies of the same domain in different countries is worth conducting. Additionally, it is advisable to employ multiple pragmatic perspectives, such as adaptability (e.g.,Verschueren, 1999) and politeness (e.g., Leech, 1987) to interpret corporate apologies so as to gain a more comprehensive understanding of this phenomenon.

\section{Acknowledgments}

The authors gratefully acknowledge the research grant (17SS03) delivered by Guandong University of Foreign Studies, and the support provided by the Research Centre for Business Culture and Philosophy of Culture, Guangdong University of Foreign Studies.

\section{References}

Austin, J. L. (1962). How to do things with words. Oxford: Oxford University Press.

Benoit, W. L. \& Brinson, S. L. (1994). At\&t: “apologies are not enough”. Communication Quarterly, 42(1), 75-88. https://doi.org/10.1080/01463379409369915

Benoit, W. L. (1995). Accounts, excuses, and apologies: A theory of image restoration strategies. State University of New York Press, Albany.

Benoit, W. L. (1997). Image repair discourse and crisis communication. 23(2), 177-186. https://doi.org/10.1016/S0363-8111(97)90023-0

Benoit, W. L. \& Shirley, D. (1997). Appropriateness and effectiveness of image repair strategies. Communication Reports, 10(2), 153-163. https://doi.org/10.1080/08934219709367671

Bhatia, V. K. (1993). Analyzing genre: Language use in professional settings. London/New York: Longman.

Blum-Kulka, Shoshana, House, Juliane, Kasper \& Gabriele. (1989). Cross-cultural pragmatics: requests and apologies. Ablex.

Brown, P. B. (1987). Politeness: Some universals in language usage. Cambridge University Press.

Burns, J. P. \& Bruner, M. S. (2000). Revisiting the theory of image restoration strategies. Communication Quarterly, 48(1), 27-39. https://doi.org/10.1080/01463370009385577

Burnett, T. (2002). Mass public corporate apology. Dispute Resolution Journal.

Conklin, D. W. (2005). Cross-border mergers and acquisitions: A response to environmental transformation. Journal of World Business, 40(1), 29-40. https://doi.org/10.1016/j.jwb.2004.10.003

Coombs, W. T. (1999). Information and compassion in crisis responses: A test of their effects. Journal of Public Relations Research, 11, 125-143.

Coombs, W. T. (2004). West Pharmaceutical's explosion: structuring crisis discourse knowledge. Public Relations Review, 30(4), 467-473. https://doi.org/10.1016/j.pubrev.2004.08.007

Coombs, W. T. \& Holladay, S. J. (2002). Helping crisis managers protect reputational assets initial tests of the situational crisis communication theory. Management Communication Quarterly, 16(2), 165-186. https://doi.org/10.1177/089331802237233

Coombs, W. T. \& Holladay, S. J. (2008). Comparing apology to equivalent crisis response strategies: Clarifying apology's role and value in crisis communication. Public Relations Review, 34(3), 252-257. 
https://doi.org/10.1016/j.pubrev.2008.04.001

Compton, J. (2016). Sorry sorries: Image repair after regretted apologies. Public Relations Review, 42(2), 353-358. https://doi.org/10.1016/j.pubrev.2016.01.002

Du Plessis, C. (2018). Social media crisis communication: Enhancing a discourse of renewal through dialogic content. Public Relations Review, 44(5), 829-838. https://doi.org/10.1016/j.pubrev.2018.10.003

Fediuk, T. A., Pace, K. M. \& Botero, I. C. (2010). Crisis response effectiveness: Methodological considerations for advancement in empirical investigation into response impact. In the Handbook of Crisis Communication (pp. 221-242). https://doi.org/10.1002/9781444314885.ch10

Fortunato, J. A. (2008). Restoring a reputation: The Duke University lacrosse scandal. Public Relations Review, 34(2), 116-123. https://doi.org/10.1016/j.pubrev.2008.03.006

García, C. (2011). Sex scandals: A cross-cultural analysis of image repair strategies in the cases of Bill Clinton and Silvio Berlusconi. Public Relations Review, 37(3), 292-296. https://doi.org/10.1016/j.pubrev.2011.03.008

Ihlen, O. (2002). Defending the mercedes a-class: combining and changing crisis-response strategies. Journal of Public Relations Research, 14(3), 185-206. https://doi.org/10.1207/S1532754XJPRR1403_2.

Jing, H. (2005). A multidimensional perspective on speech acts of apology (unpublished thesis). Shandong University, China.

Jingjie, H. (2012). A cross-cultural analysis of American and Chinese corporate apologies (unpublished thesis). Fudan University, China.

Jun, L. (2007). An analysis of the discourse patterns and pragmatic characteristics of apologizing in Chinese. Language Teaching and Linguistic Studies, (01), 11-19.

Kampf, Z. (2009). Public (non-) apologies: the discourse of minimizing responsibility. Journal of Pragmatics, 41(11), 0-2270. https://doi.org/10.1016/j.pragma.2008.11.007

Kauffman, J. (2012). Hooray for Hollywood? The 2011 Golden Globes and Ricky Gervais' image repair strategies. Public Relations Review, 38(1), 46-50. https://doi.org/10.1016/j.pubrev.2011.09.003

Kim, P. H., Ferrin, D. L., Cooper, C. D. \& Dirks, K. T. (2004). Removing the shadow of suspicion: the effects of apology versus denial for repairing competence- versus integrity-based trust violations. Journal of Applied Psychology, 89(1), 104-18. https://doi.org/10.1037/0021-9010.89.1.104

King, G. (2006). Image restoration: An examination of the response strategies used by Brown and Williamson after allegations of wrongdoing. Public Relations Review, 32(2), 131-136. https://doi.org/10.1016/j.pubrev.2006.02.006

Kuhn, E. D., Blum-Kulka, S., House, J. \& Kasper, G. (1991). Cross-cultural pragmatics: requests and apologies. Language, 67(1), 169. https://doi.org/10.2307/415556

Leech, G.N. (1983). Principles of Pragmatics. London: Longman.

Lee, S. \& Chung, S. (2012). Corporate apology and crisis communication: The effect of responsibility admittance and sympathetic expression on public's anger relief. Public Relations Review, 38(5), 932-934. https://doi.org/10.1016/j.pubrev.2012.08.006

Meng, J. (2010). SK-II China and its skin cream scandal: An extended analysis of the image restoration strategies in a non-Western setting. Public Relations Review, 36(1), 66-69. https://doi.org/10.1016/j.pubrev.2009.10.004

Muralidharan, S., Dillistone, K. \& Shin, J. H. (2011). The Gulf Coast oil spill: Extending the theory of image restoration discourse to the realm of social media and beyond petroleum. Public Relations Review, 37(3), 226-232. https://doi.org/10.1016/j.pubrev.2011.04.006

Olshtain, E. \& Cohen, A. D. (1983). Apology: A speech act set. In N. Wolfson \& E. Judd (Eds.). Sociolinguistics and Language Acquisition, (pp.18-35). Rowley, MA: Newbury.

Qinghong, S. (2005). Experimental research on the evaluation of internet corporation based on customers. Network Security Technology \& Application, (04), 34-37. https://doi.org/CNKI:SUN:WLAQ.0.2005-04-013

Raju, S. \& Rajagopal, P. (2008). Responding to ethical and competence failures. Advances in Consumer Research. 
Rasmussen, L. (2015). Planned Parenthood takes on Live Action: An analysis of media interplay and image restoration strategies in strategic conflict management. Public Relations Review, 41(3), 354-356. https://doi.org/10.1016/j.pubrev.2015.01.004

Ruth, P. (2014). Saying 'sorry': corporate apologies posted on twitter. Journal of Pragmatics, 62, 30-45. https://doi.org/10.1016/j.pragma.2013.12.003

Schumann, K. (2014). An affirmed self and a better apology: the effect of self-affirmation on transgressors' responses to victims. Journal of Experimental Social Psychology, 54, 89-96. https://doi.org/10.1016/j.jesp.2014.04.013

Searle, J. R. (1976). A classification of illocutionary acts. Language in Society, 5(1), 1-23. https://doi.org/10.1017/S0047404500006837

Senlin, L. (2003). Pragmatic strategies and speech act. Foreign Language Education, 024(003), 10-15. https://doi.org/10.3969/j.issn.1000-5544.2003.03.003

Swales, J. M. (1990). Genre analysis: English in academic and research settings. Cambridge: Cambridge University Press.

Ten Brinke, L. \& Adams, G. S. (2015). Saving face? When emotion displays during public apologies mitigate damage to organizational performance. Organizational Behavior \& Human Decision Processes, 130, 1-12. https://doi.org/10.1016/j.obhdp.2015.05.003

Triantafillidou, A. \& Yannas, P. (2020). Social media crisis communication in racially charged crises: Exploring the effects of social media and image restoration strategies. Computers in Human Behavior, 106, 106269. https://doi.org/10.1016/j.chb.2020.106269

Trosborg, A. (1987). Apology strategies in natives/non-natives. Journal of Pragmatics, 11(2), 147-167.

Ulmer, R. R., Seeger, M. W. \& Sellnow, T. L. (2007). Post-crisis communication and renewal: Expanding the parameters of post-crisis discourse. Public Relations Review, 33(2), 130-134. https://doi.org/10.1016/j.pubrev.2006.11.015

Verhoeven, J. W. M., Van Hoof, J. J., Ter Keurs, H. \& Van Vuuren, M. (2012). Effects of apologies and crisis responsibility on corporate and spokesperson reputation. Public Relations Review, 38(3), 501-504. https://doi.org/10.1016/j.pubrev.2012.02.002

Verschueren, J. (1998). Understanding Pragmatics. London: Arnold.

Xiaopeng, L. \& Li, L. (2012). Research on the evolution of internet enterprise business model in its life cycle - A case study of Tencent. Economic Management Journal, 34(2), 183-192.

Yueguo, G. (1989). Austin's speech act theory: What it is and where it is wrong. Foreign Language Teaching and Research, (1), 30-39+80.

Yueguo, G. (1994). John Searle's speech act theory: Evaluation and reference. Linguistics Abroad, (3), 10-16.

Yuande, Z. \& Xiuqing, Z. (2001). Research on multi-level weight analysis of M\&A risk. Technology Economics, (11), 52-53.

Zhixia, G. \& Lei, W. (2012). Analysis and prevention of financial risks of enterprises' cross-border M\&A. Communication of Finance and Accounting, (5), 147-149.

\section{Copyrights}

Copyright for this article is retained by the author(s), with first publication rights granted to the journal.

This is an open-access article distributed under the terms and conditions of the Creative Commons Attribution license (http://creativecommons.org/licenses/by/4.0/). 